\title{
Accounts
}

\section{Proton Transfer in Biomolecules Facilitated by Water: Quantum Chemical Investigations}

\author{
Sungyul Lee \\ Department of Applied Chemistry, College of Applied Sciences, Kyung Hee University, Kyungki 446-701, Korea \\ E-mail:sylee@khu.ac.kr \\ Received January 26, 2011, Accepted February 24, 2011
}

\begin{abstract}
We present a brief review for theoretical/computational studies of proton transfer processes of some simple biomolecules promoted by microsolvating water molecules. Focus is given on the relative stability of the canonical vs. zwitterionic forms of amino acids, tautomeric forms of the DNA base adenine, and the biologically active vs. inactive forms of nicotine. The biochemical implications of these findings are also discussed.
\end{abstract}

Key Words : Proton transfer, Biomolecule, Water

\section{Introduction}

Proton transfer ${ }^{1-5}$ is one of the most fundamental and elementary chemical processess. Acid-base chemistry is essentially the proton transfer process in aqueous solution. Many chemical species in cell are acid or base, and their biochemical activity depends critically on whether they are in protonated or deprotonated form. While the proton donor itself is generally unsolvated in the gas phase, proton transfers in condensed phases involve solvated protons, generally the conjugate acid of the solvent. One salient example is the case of amino acids and peptides, which are in zwitterionic form in aqueous solution by intramolecular proton transfer from the carboxyl to amino moiety.

The role of solvent in proton transfer in biomolecules may be either direct or indirect. Aprotic solvents may not significantly affect the rate of proton transfer process, acting mainly as electrostatic continuum, whereas protic solvents such as water or alcohol exert much stronger influence on the thermodynamics and/or kinetics of the process. Although the dynamic processes of proton transfer are hard to observe experimentally, recent progress in quantum chemical methods now renders such a study quite feasible.

In this brief review, we describe quantum chemical investigations recently carried out in our laboratory employing the GAUSSIAN 03 set of programs ${ }^{6}$ for the role of water in proton transfer in biomolecules. Energies, Gibbs free energies (at $5 \mathrm{~K}$ for sections 1 and 2, and at $298 \mathrm{~K}$ for section 3), and the activation barriers were evaluated for typical biomolecules (amino acids, DNA base and nicotine) to analyze the effects of water on their structures and dynamics. We have found that the role of water is profound: the microsolvating water molecules either take part in the process directly (mediating the movement of the proton), or even accelerating it. We first discuss the thermodynamic and kinetic stability of zwitterionic amino acids relative to canonical forms as a function of the number of microsolvating water molecules, thereby elucidating how many molecules are necessary to stabilize the zwitterion. Second, we describe the effects of water on the tautomerization of adenine to study the origin of experimental observation of multiple tautomers in aqueous solution. Finally, we describe our recent study of water-mediated proton transfer in nicotine between the biologically active and inactive forms.

\section{Stability of Canonical vs. Zwitterionic Forms of Amino} Acids.

Solvation of amino acids ${ }^{7-14}$ by water has been under intensive study both theoretically and experimentally, because the structures and stability of canonical ${ }^{15-18}$ and zwitterionic $^{16,19-25}$ forms are profoundly affected by solvent. Amino acids exist in canonical (nonzwitterionic) form in the gas phase, whereas zwitterionic (charge-separated) conformer is the predominant in aqueous solution. ${ }^{24-27}$ One of the
Sungyul Lee earned his BS degree from Seoul National University in 1977 and his MS degree from KAIST in 1979. In 1988, he received his $\mathrm{Ph} \mathrm{D}$ degree in physical chemistry from the Department of Chemistry, University of Chicago under the supervision of Prof. K. F. Freed. He was appointed to Assistant, Associate, and Professor at Kyung Hee University from 1989 to present. He has been a visiting scholar at University of Houston in 1996, and from 2004 to 2005 at UCLA. His research interest is focused on the effects of water on the structures and reactivity of biomolecules, solvent catalysis (protic solvents, ionic liquids) of organic reactions, quantum chemical study the mechanism of organometallic and organocatalytic reactions, and materials chemistry. Professor Lee received the renowned Lee Tae-Kyu award from the Korean Chemical Society in 2009. 
central questions concerning the structures and biochemical properties of amino acids is: How many water molecules are required to stabilize the zwitterionic form? This question has been addressed both theoretically and experimentally by examining the relative stability of these two forms as a function of the number of microsolvating water molecules. There was, however, a fundamental difference between the experimental observations and theoretical predictions: While the experiments concluded that the transition from the canonical to zwitterionic form starts with four to five water molecules, ${ }^{7,27,28}$ theoretical calculations indicated that at least seven water molecules ${ }^{29}$ are required to stabilize the zwitterion. The basis of the latter prediction was purely thermodynamic, that is, the relative Gibbs free energy of canonical and zwitterionic forms. It seemed that the thermodynamic grounds given by the theoreticians seemed to be lacking the kinetic aspects of the problem, the latter viewpoint being very important especially in low temperature $(\sim 5 \mathrm{~K})$ gas phase. We carried out calculations for the structures of amino acids (glycine, alanine, serine and arginine) water clusters and for the dynamic pathways of canonical $\leftrightarrow$ zwitterionic transformation, to examine the relative Gibbs free energy of the two species and the reaction barriers of isomerization. We have found a variety of behaviors for these amino acids.

Alanine: The computed structure of the lowest energy alanine- $\left(\mathrm{H}_{2} \mathrm{O}\right)_{2}$ with the canonical Ala core is presented in Figure 1-1-1. ${ }^{15}$ We found that the first stationary Ala- $\left(\mathrm{H}_{2} \mathrm{O}\right)_{n}$ cluster with Ala zwitterion is for $n=2$, indicating that at least two water molecules are needed to stabilize the Ala zwitterion. Besides the fact that the Ala- $\left(\mathrm{H}_{2} \mathrm{O}\right)_{2}$ clusters with zwitterionic Ala are higher in energy (by $>5 \mathrm{kcal} / \mathrm{mol}$ ), however, they transform to canonical Ala- $\left(\mathrm{H}_{2} \mathrm{O}\right)_{2}$ via very small barrier $(<2 \mathrm{kcal} / \mathrm{mol})$, as depicted in Figure 1-1-2. Therefore, the zwitterionic Ala- $\left(\mathrm{H}_{2} \mathrm{O}\right)_{\mathrm{n}}$ is not stable both thermodynamically and kinetically, indicating that two water molecules, acting as a bridge mediating the concerted double proton transfer processes as depicted in Figure 1-1-2, are not

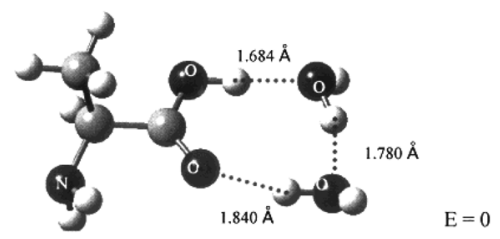

Figure 1-1-1. Structure of the lowest energy alanine- $\left(\mathrm{H}_{2} \mathrm{O}\right)_{2}$ with the canonical Ala core.

enough to stabilize it.

Serine: The lowest energy structures of the serine - $\left(\mathrm{H}_{2} \mathrm{O}\right)_{2}$ cluster with canonical and zwitterionic serine (Ser) are presented in Figure 1-2-1. These structures are quite close in energy (within $\sim 3 \mathrm{kcal} / \mathrm{mol}$ ). ${ }^{16}$ Since the energies of Ser-

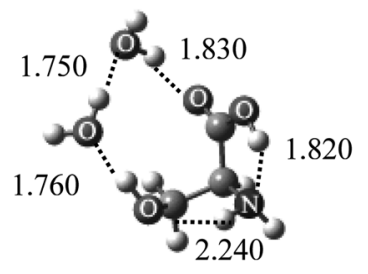

N2-2-a $\quad(\Delta E=1.3)$

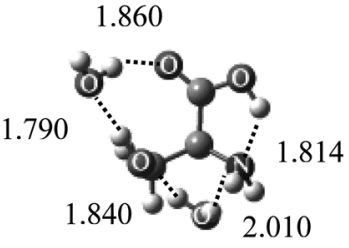

$\mathrm{N} 2-2-\mathrm{b}(\Delta E=2.2)$

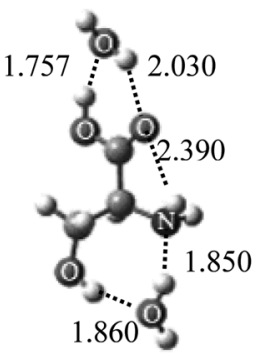

$\mathrm{N} 1-2(\Delta E=2.7)$

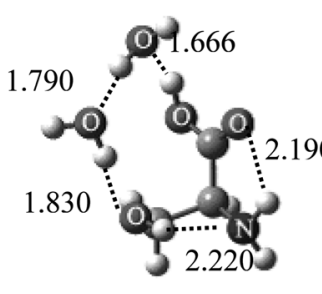

N3-2-a $\quad(E=0)$

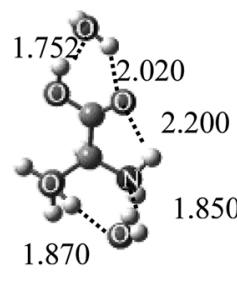

$\mathrm{N} 3-2-\mathrm{b}(\Delta E=3.1)$
Figure 1-2-1. Lowest-lying conformers of canonical serine $\left(\mathrm{H}_{2} \mathrm{O}\right)_{2}$ lowest energy conformers.

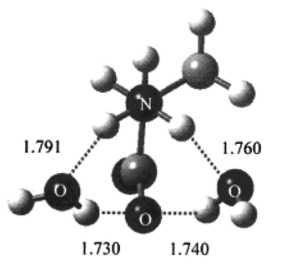

Z2-3

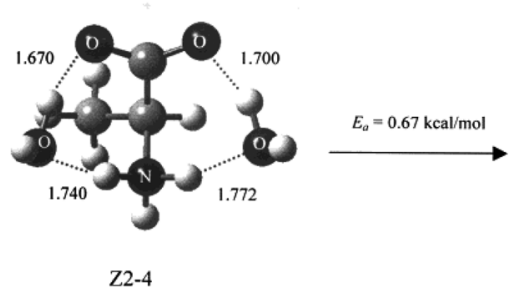

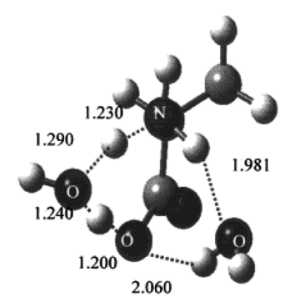

T3

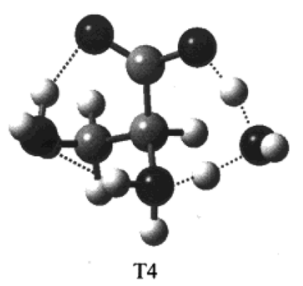

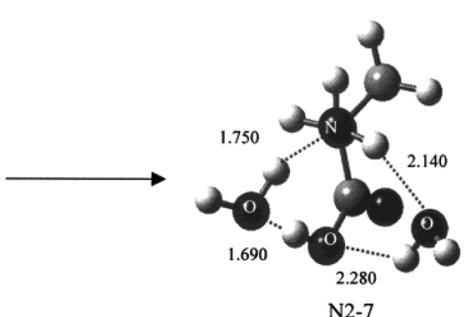

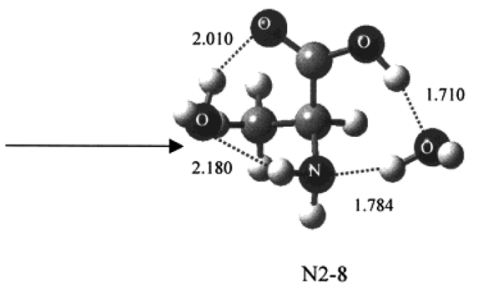

Figure 1-1-2. Concerted double proton transfer pathways from the alanine zwitterion- $\left(\mathrm{H}_{2} \mathrm{O}\right)_{2}$ clusters to the canonical clusters (bond distances in A). 


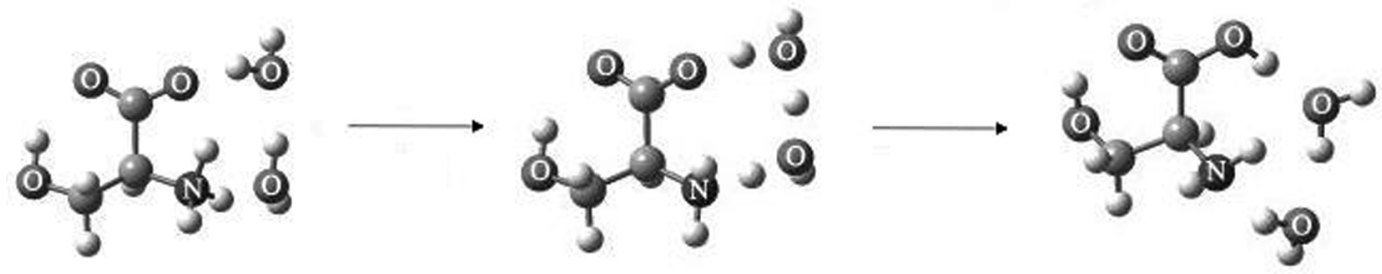

Figure 1-2-2. Mechanism of canonical $\leftrightarrow$ zwitterion isomerization of serine $-\left(\mathrm{H}_{2} \mathrm{O}\right)_{2}$ (reaction barrier in $\left.\mathrm{kcal} / \mathrm{mol}\right)$.

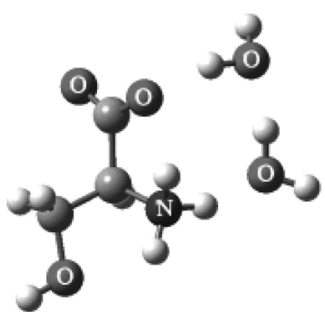

Z2-1

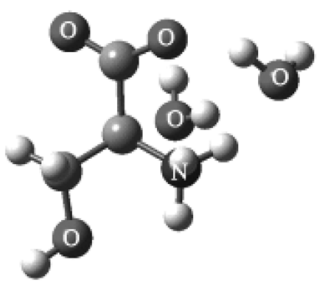

Z2-2

Figure 1-2-3. Kinetically stable zwitterionic serine - $\left(\mathrm{H}_{2} \mathrm{O}\right)_{2}$.

$\left(\mathrm{H}_{2} \mathrm{O}\right)_{2}$ with zwitterionic Ser are calculated to be at least 6 $\mathrm{kcal} / \mathrm{mol}$ higher than those given in Figure 1-2-1, they are considered to be unstable thermodynamically. Most of the zwitterionic $\left(\mathrm{H}_{2} \mathrm{O}\right)_{2}$ isomerize to canonical forms without significant barriers, however, some may isomerize to the canonical form by considerable barriers, for example, the (Z2-6) conformer via a fairly large barrier $(6.2 \mathrm{kcal} / \mathrm{mol})$. Some of these possibly "kinetically stable" conformers are listed in Figure 1-2-3.

Glycine: The lowest energy structures of the glycine $\left(\mathrm{H}_{2} \mathrm{O}\right)_{5}$ cluster with canonical and zwitterionic glycine (Gly) core presented in Figure 1-3-1 are quasidegenerate, the zwitterionic structure lying only $1.6 \mathrm{kcal} / \mathrm{mol}$ higher than the canonical form. ${ }^{14}$ This finding is in high contrast with the case of smaller Gly - $\left(\mathrm{H}_{2} \mathrm{O}\right)_{3}$ clusters, in which the zwitterionic Gly is of much higher energy than the canonical forms. ${ }^{14(b)}$ On purely thermodynamical sense, it may be said that five water molecules are not enough to stabilize the

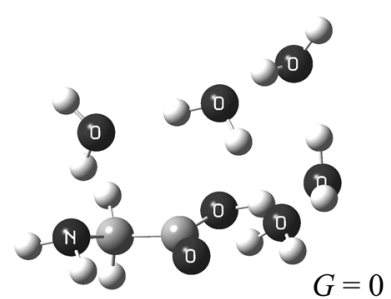

canonical

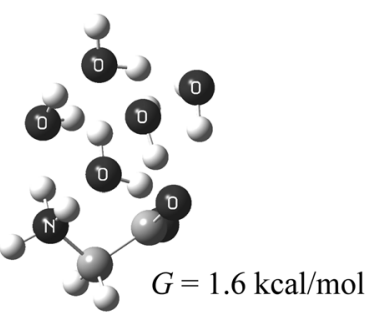

zwitterion

Figure 1-3-1. Structures of the lowest energy conformers of canonical Gly - $\left(\mathrm{H}_{2} \mathrm{O}\right)_{5}$.

zwitterionic Gly. The dynamic pathway for the canonical $\leftrightarrow$ zwitterion transformation depicted in Figure 1-3-2, however, indicates otherwise. Although the canonical Gly - $\left(\mathrm{H}_{2} \mathrm{O}\right)_{5}$ is calculated to be a bit more stable than the zwitterionic form, the latter structure may still be observed in low temperature gas phase environment if they may survive long enough. The barrier of isomerization is a critical property determining the kinetic stability of the zwitterionic species, because it describes the ease with which they may transform. Figure 1-3-2 shows that the lowest energy canonical Gly $\left(\mathrm{H}_{2} \mathrm{O}\right)_{5}$ transforms to a zwitterionic form via a substantial barrier $(8.8 \mathrm{kcal} / \mathrm{mol})$, in high contrast with the zwitterionic Gly - $\left(\mathrm{H}_{2} \mathrm{O}\right)_{3}$ clusters that isomerize to the canonical forms via barrierless proton transfer processes. This fairly large barrier to isomerization may kinetically separate the zwitterionic and the canonical Gly - $\left(\mathrm{H}_{2} \mathrm{O}\right)_{5}$, rendering them observable at least in the gas phase at low temperature. We think

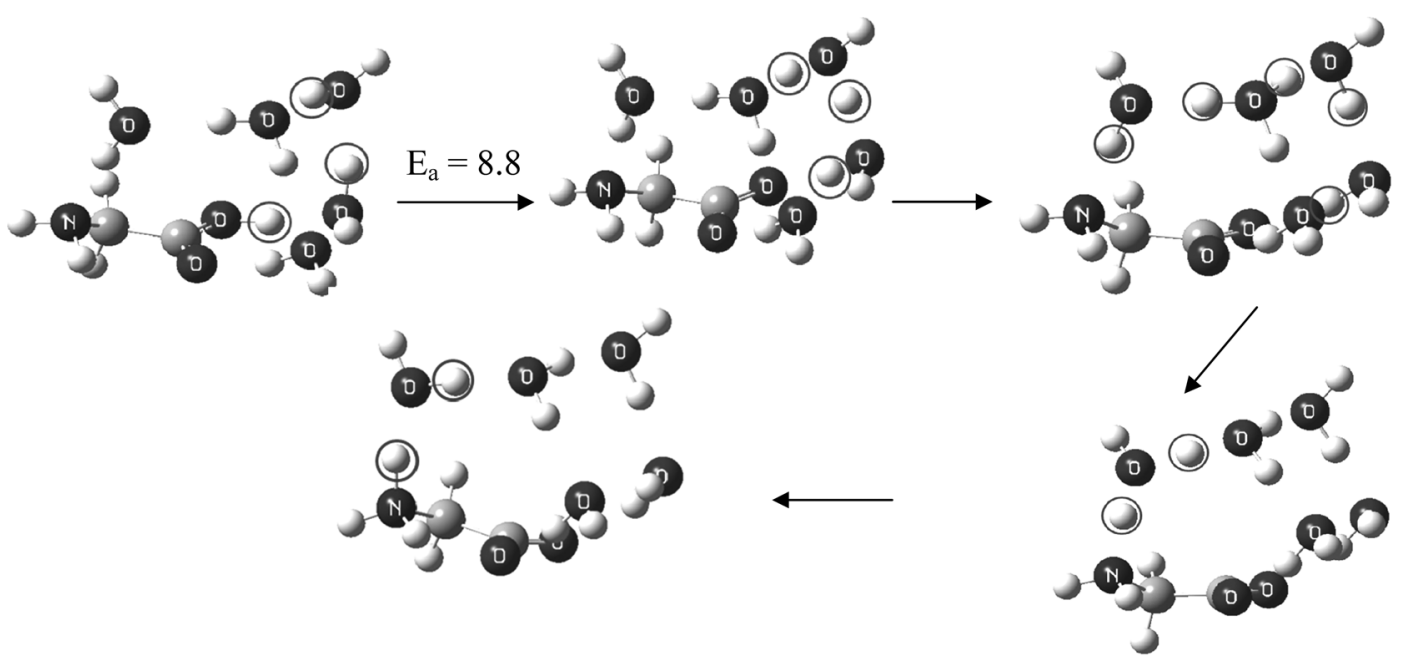

Figure 1-3-2. canonical $\leftrightarrow$ zwitterion transformation of $\mathrm{Gly}-\left(\mathrm{H}_{2} \mathrm{O}\right)_{5}$ (barrier in kcal/mol) (MP2/aug-cc-pvdz). 
that the presumed kinetic stability of the zwitterionic species of Gly - $\left(\mathrm{H}_{2} \mathrm{O}\right)_{5}$ seems to resolve the disagreement between the experimental observations and theoretical predictions concerning the number of water molecules to stabilize the amino acid zwitterion, and that Gly $-\left(\mathrm{H}_{2} \mathrm{O}\right)_{5}$ may indeed be the threshold to the stabilized zwitterion.

Arginine: Although arginine $(\mathrm{Arg})^{30-35}$ is similat to other amino acids in that the canonical form is only observed in the gas phase, the presence of the strongly basic guanidine sidechain in Arg may give properties that are distinct from the other amino acids. For example, the strongly basic guanidine sidechain may render the proton transfer from the carboxyl group much more facile under the influence of solvent. Figure 1-4-1 and 1-4-2 present the calculated structures and relative energy of the zwitterionic and canonical conformers of $\mathrm{Arg}-\mathrm{H}_{2} \mathrm{O}$. We found that the energy of the conformer (Z22-1) with the zwitterionic Arg core is lower than those of the lowest energy canonical form (C5-1) by 2 $\mathrm{kcal} / \mathrm{mol}$ by B3LYP/6-311++G** method. This observation is quite striking, considering that the zwitterionic Arg is at least $3 \mathrm{kcal} / \mathrm{mol}$ higher in energy than the canonical Arg. ${ }^{36} \mathrm{It}$ is also remarkable to observe that a single microsolvating water molecule may stabilize the zwitterionic Arg relative to the canonical form, because it was well agreed that at least three to five molecules of water are necessitated to make the zwitterionic form energetically competitive with the canonical conformer. It must be noted that proton is transferred from the carboxyl to the sidechain guanidine group in Arg, in contrast with other amino acids. The two Zwitterionic conformers (Z22-1) and (Z21-2) depicted in Figure 1-4-1 are almost of the same energy (within $0.5 \mathrm{kcal} /$
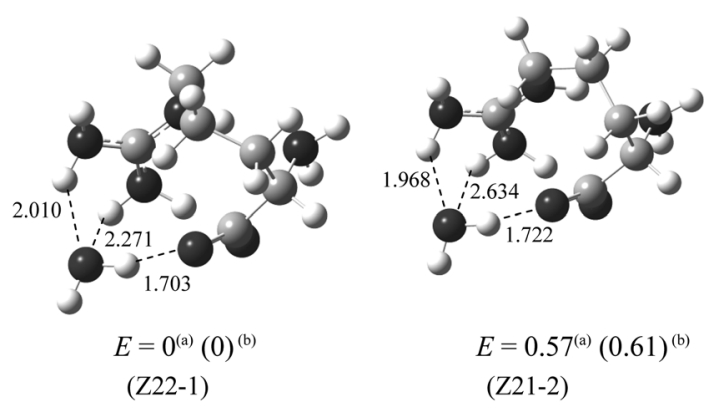

Figure 1-4-1. Structures of the lowest energy conformers of zwitterionic Arg $-\mathrm{H}_{2} \mathrm{O}$ (relative energy in $\mathrm{kcal} / \mathrm{mol}$ and bond lengths in $\AA$ ). (a) B3LYP/6-311++G** (b) MP2/aug-cc-pvdz mol).

Figure 1-4-2 depicts the structures and relative energies of the canonical Arg $-\mathrm{H}_{2} \mathrm{O}$. We find that the low energy conformers of $\mathrm{Arg}-\mathrm{H}_{2} \mathrm{O}$ with canonical Arg core are produced mainly from the lowest energy canonical Arg, (C4) and (C5) (see Ref. [36]). The three lowest energy canonical conformers (C4-1), (C4-7), and (C5-1) are very similar in energy, to within $0.3 \mathrm{kcal} / \mathrm{mol}$.

One important issue would be the mechanism and the barrier of formation of the zwitterionic Arg - $\left(\mathrm{H}_{2} \mathrm{O}\right)$ from canonical conformer. If the $\operatorname{Arg}-\left(\mathrm{H}_{2} \mathrm{O}\right)$ complex initially produced with canonical Arg core is kinetically very stable (that it, if the barrier to zwitterionic $\mathrm{Arg}-\left(\mathrm{H}_{2} \mathrm{O}\right)$ is high), the latter form of Arg - $\left(\mathrm{H}_{2} \mathrm{O}\right)$ could hardly be formed. The barrier from the canonical form to zwitterion is $\sim 4.5 \mathrm{kcal} /$ mol, indicating that the canonical conformer of $\operatorname{Arg}-\left(\mathrm{H}_{2} \mathrm{O}\right)$, once formed, may easily transform to zwitterion. Figure 1-43 also depicts that the lowest energy zwitterionic form (Z221) connects via a double proton transfer process to canonical form.

\section{Tautomerization of Adenine.}

Tautomers of adenine have been studied mostly focusing on the relative stability and abundance. It is known that $9(\mathrm{H})$ adenine is the lowest-energy conformer in the gas phase, and

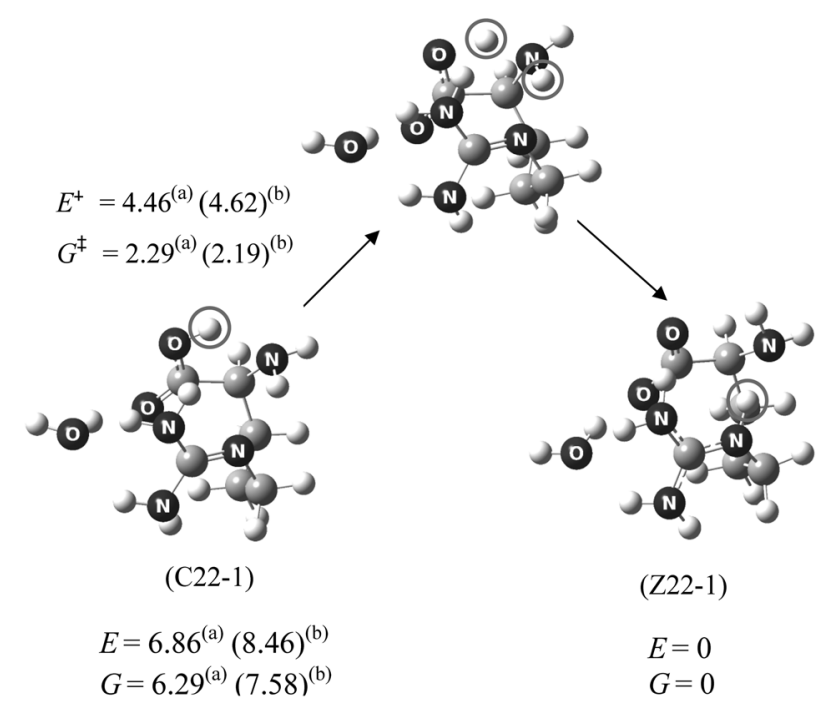

Figure 1-4-3. Isomerization from the canonical form of $\mathrm{Arg}-\mathrm{H}_{2} \mathrm{O}$ to the zwitterionic form (relative energy in $\mathrm{kcal} / \mathrm{mol}$, ZPE included; (a) B3LYP/6-311++G** (b) MP2/6-311+G*).
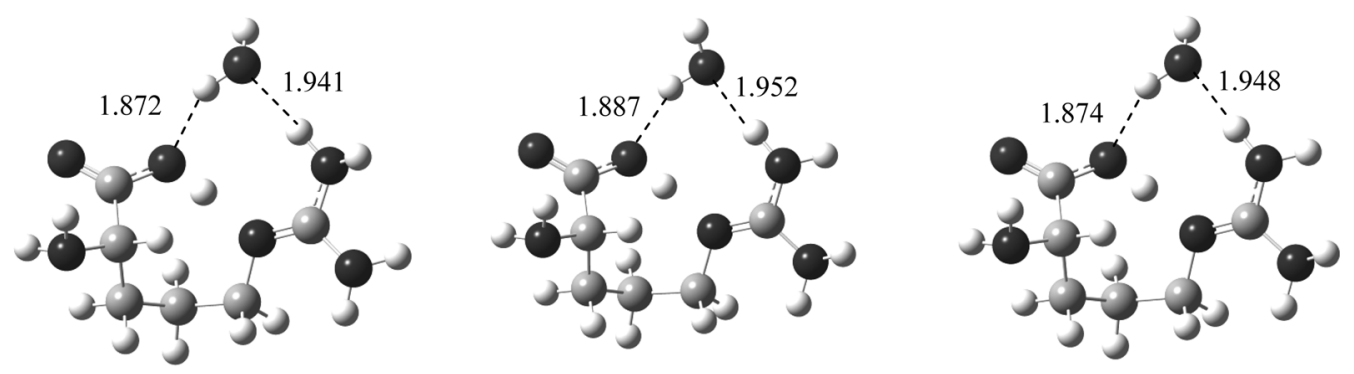

Figure 1-4-2. Structures of the low energy conformers of canonical Arg - $\mathrm{H}_{2} \mathrm{O}$ (relative energy with respect to (Z22-1) in kcal/mol). (a) B3LYP/6-311++G** (b) MP2/aug-cc-pvdz. 
that the $7(\mathrm{H})$ and $3(\mathrm{H})$ tautomers are much higher in energy. In the solution phase, however, the $9(\mathrm{H}), 7(\mathrm{H})$ and $3(\mathrm{H})$ adenine have been found to coexist, ${ }^{37,38}$ suggesting that the $7(\mathrm{H})$ and $3(\mathrm{H})$ tautomers may be stable and abundant due to the effects of interactions with solvent. We calculate (Figure 2-1) that the $7(\mathrm{H})$ and $3(\mathrm{H})$ adenine are $8.4(7.7)$ and 8.2 (7.6) $\mathrm{kcal} / \mathrm{mol}$, respectively, above the $9(\mathrm{H})$ tautomer at B3PW91/6-311+G(d,p) (MP2/6-311+G(d,p)) level of theory. ${ }^{39}$ Our calculated relative energies are in good agreement with those obtained by Hobza and co-workers, ${ }^{40}$ who employed the MP2/aug-cc-pVDZ//RI-MP2/TZVPP method. Considering the high relative energy $(8.2-8.4 \mathrm{kcal} / \mathrm{mol})$ of the $7(\mathrm{H})$ and $3(\mathrm{H})$ tautomers relative to the $9(\mathrm{H})$ adenine, it seems that they are not to be observed in the gas phase.

We find various competing reaction pathways for tautomerization from $9(\mathrm{H})$ to $7(\mathrm{H})$ adenine in the gas phase. Figure 2-2 depicts the pathway in which the $9(\mathrm{H})$ adenine tautomerizes to $3(\mathrm{H})$ and $7(\mathrm{H})$ tautomers in the absence of water. The mechanism begins with the $9(\mathrm{H}) \rightarrow 3(\mathrm{H})$ tautomerization, followed by proton transfer from the amino

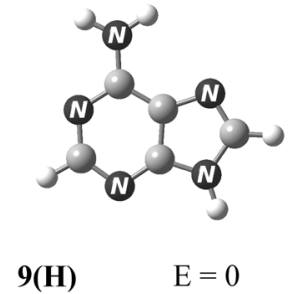

(a) B3PW91/6-311+G(d,p)

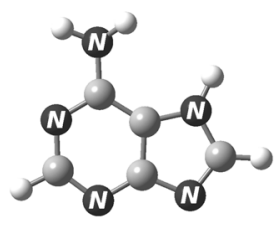

7(H)

(b) MP2/6-311+G(d,p)

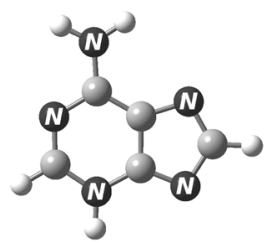

3(H) $\quad \mathrm{E}=8.2^{(\mathrm{a})}, 7.6^{(\mathrm{b})}, 3.9^{(\mathrm{c})}$

(c) B3PW91/6-311+G(d,p)/IEFPCM

Figure 2-1. Structures and relative energies $(\mathrm{kcal} / \mathrm{mol})$ of adenine tautomers.

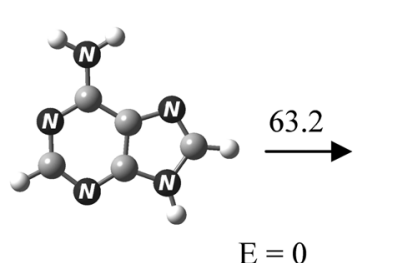

9(H)

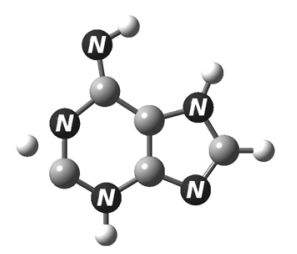

TS4

68.4

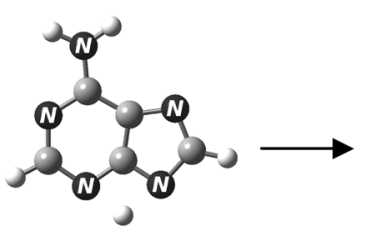

TS1

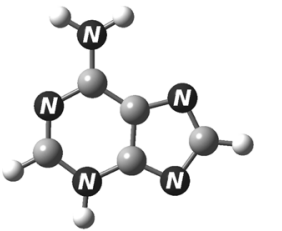

37.7

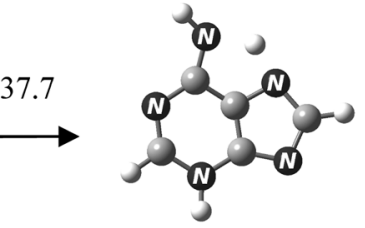

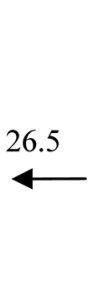

TS3

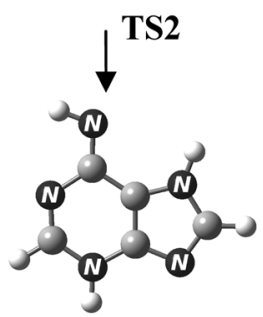

IM1

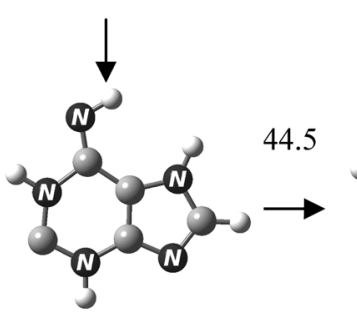

IM3 $\mathrm{E}=43.8$
IM2 $\mathrm{E}=24.6$

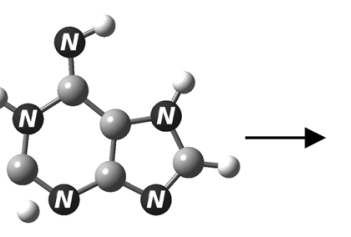

TS5

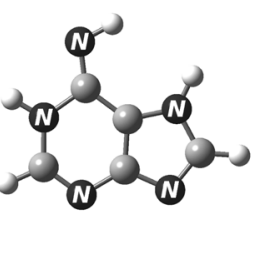

IM4 $E=16.6$
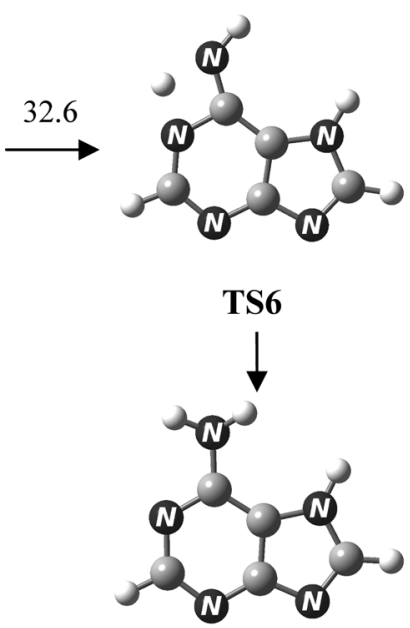

7(H) $\quad \mathrm{E}=8.4$

Figure 2-2. 9(H) 3(H) 7(H) tautomerization via imine intermediates (B3PW91/6-311+G(d,p)) (Barriers and relative energies in kcal/mol). 
group to 7-N atom. A series of proton transfer occurs between the neighboring $\mathrm{C}$ and $\mathrm{N}$ atoms, eventually regenerating the amino group and producing the $7(\mathrm{H})$ adenine. The barrier in the rate-determining step (IM2 $\rightarrow$ IM3) of the $9(\mathrm{H}) \rightarrow 7(\mathrm{H})$ tautomerization in the imine mechanism is extremely high $(68 \mathrm{kcal} / \mathrm{mol})$, presumably because the process involves an awkward proton transfer between the neighboring $\mathrm{N}$ and $\mathrm{C}$ atoms. The large overall barrier in the imine mechanism depicted in Figure 2-2 may also make the $9(\mathrm{H}) \rightarrow 7(\mathrm{H})$ tautomerization very difficult to occur. The first step in the imine mechanism is the $9(\mathrm{H}) \rightarrow 3(\mathrm{H})$ tautomerization, and the process involves a transfer of a hydrogen atom from $9-\mathrm{N}$ to $3-\mathrm{N}$ with large barrier $(63 \mathrm{kcal} /$ mol). Thus, it seems that the $9(\mathrm{H}) \rightarrow 3(\mathrm{H})$ tautomerization would not proceed readily in the gas phase. Therefore, the presence of $7(\mathrm{H})$ and $3(\mathrm{H})$ tautomers in aqueous solution may be attributed to the effects solvent.

We found that some tautomerization pathways are profoundly affected by the microsolvating water molecules (Figure 2-3). For example, a binding water molecule drastically lowers the $9(\mathrm{H}) \rightarrow 3(\mathrm{H})$ barrier from 63 to $16 \mathrm{kcal} / \mathrm{mol}$, indicating that the water molecules act as catalyst. By carrying out the IRC analysis, we find that the mechanism of this solvent-assisted reaction is a concerted double proton transfer. Binding of two water molecules may still lower the barrier to $9.7 \mathrm{kcal} / \mathrm{mol}$, further promoting the $9(\mathrm{H}) \rightarrow 3(\mathrm{H})$ tautomerization by a concerted triple proton transfer mecha- nism. This is very interesting, because this very low barrier for the $9(\mathrm{H}) \rightarrow 3(\mathrm{H})$ tautomerization under the influence of water molecules may suggest that the $9(\mathrm{H})$ adenine is prone to isomerization to produce the $3(\mathrm{H})$ tautomer in considerable amount, as observed experimentally in the solution phase. ${ }^{37}$ We also predicted that the $7(\mathrm{H}) \leftrightarrow 9(\mathrm{H})$ tautomerization may occur directly between $9-\mathrm{N}$ and $7-\mathrm{N}$ via three water molecules by a quadruple proton transfer process. The water molecules lying above the adenine ring again acts as a "proton wire". The barrier of this process is calculated to be quite small $(\sim 20 \mathrm{kcal} / \mathrm{mol})$. These calculated results clearly indicate that the tautomerization between $7(\mathrm{H}), 9(\mathrm{H})$ and $3(\mathrm{H})$ adenine is significantly promoted by the microsolvating water molecules. Considering that these tautomers are of similar relative free energy in aqueous solution, ${ }^{39}$ our demonstrated solvent-assisted tautomerization processes may work as a key step producing the $7(\mathrm{H})$ and $3(\mathrm{H})$ tautomers in solution.

Proton Transfer between Biologically Active and Inactive Forms of Nicotine.

The role of water is crucial for the bioactivity of nicotine. It has been predicted ${ }^{41}$ and recently verified by spectroscopic methods that isolated nicotine is in its inactive form protonated on the pyridine ring. ${ }^{42}$ In aqueous solution, the protonation site shifts to the pyrrolidine ring, rendering nicotine in its active form. The hydration of nicotine and related compounds in the binding sites of the $\mathrm{nAChr}$ receptors

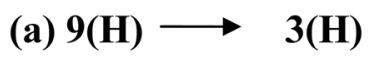

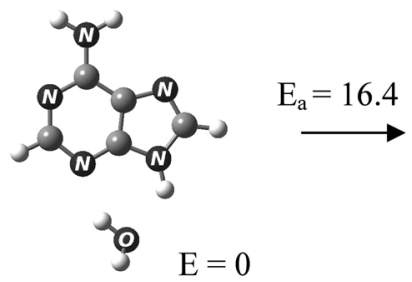

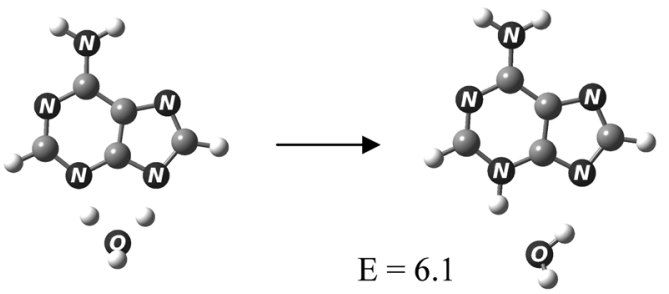

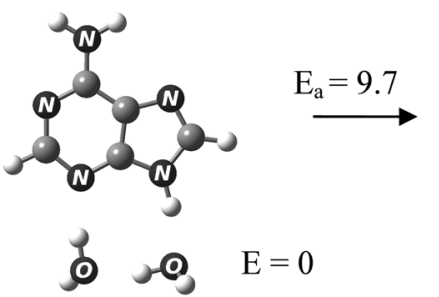

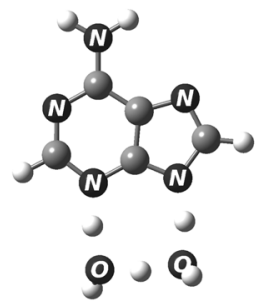

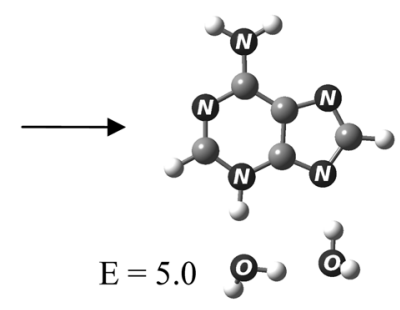

(b) 9 (H) $\longrightarrow 7(\mathrm{H})$
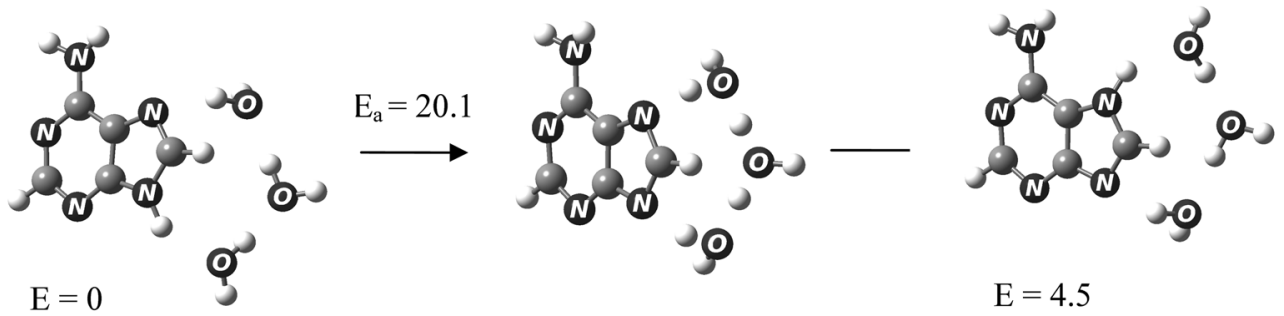

$$
\mathrm{E}=4.5
$$

Figure 2-3. Tautomerization processes facilitated by water (Barriers and relative energies in $\mathrm{kcal} / \mathrm{mol}$ ). 
(a)

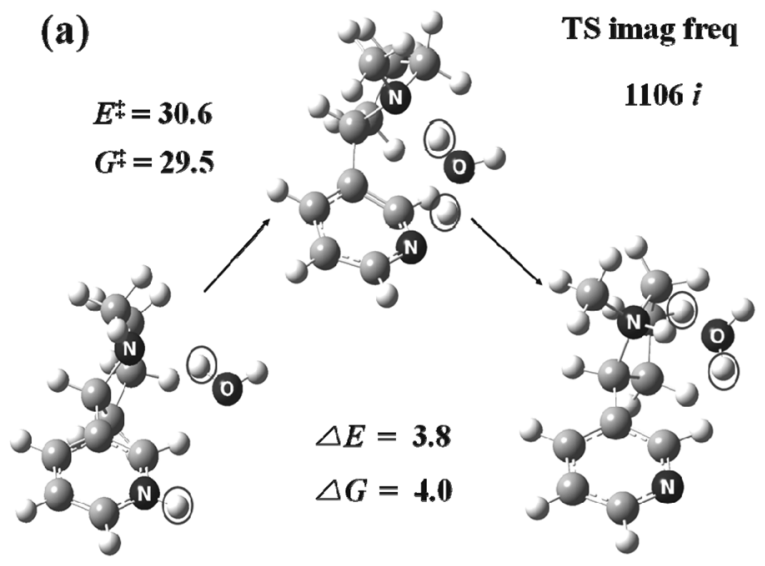

(c)

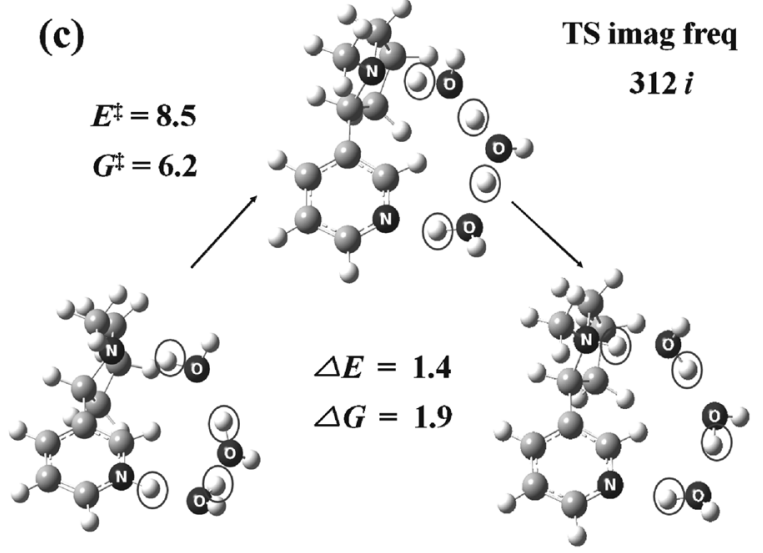

(b)
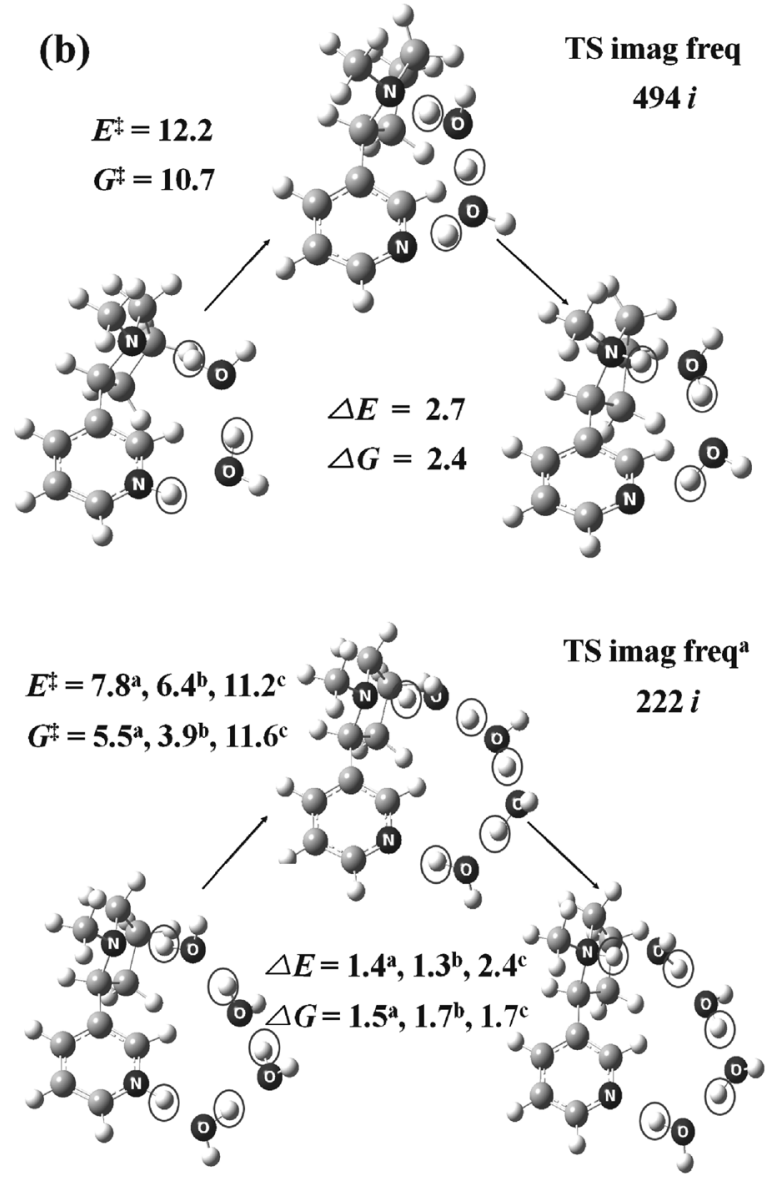

Figure 3-1. Proton transfer from the pyridine to pyrrolidine site of (a) nicotine- $\mathrm{H}^{+}-\left(\mathrm{H}_{2} \mathrm{O}\right)_{1}$, (b) nicotine $-\mathrm{H}^{+}-\left(\mathrm{H}_{2} \mathrm{O}\right)_{2}$, (c) nicotine- $\mathrm{H}^{+}-\left(\mathrm{H}_{2} \mathrm{O}\right)_{3}$, (d) nicotine- $\mathrm{H}^{+}-\left(\mathrm{H}_{2} \mathrm{O}\right)_{4}$. Barriers in $\mathrm{kcal} / \mathrm{mol}$. Computational methods: (a) B3LYP/6-311++G** (b) BLYP/6-311++G** (c) IEFPCM/ B3LYP/6-311++G**, and B3LYP/6-311++G** unless noted otherwise.

may be neither that encountered in gas-phase, nor in pure water as shown in simulations conducted with rather simple modeling of water molecule. ${ }^{43}$ Figure 3-1 demonstrates the role of water in proton between the bioactive and inactive forms of nicotine. ${ }^{44}$ The minimum energy barrier to the proton transfer from the pyridine to the pyrrolidine site becomes significantly smaller as the number of water molecules increases: it drops from $30 \mathrm{kcal} / \mathrm{mol}$ for one single water molecule down to $12 \mathrm{kcal} / \mathrm{mol}$ in the presence of two water molecules and only $8 \mathrm{kcal} / \mathrm{mol}$ for 3 water molecules. The corresponding free energies decrease from 11 to $6 \mathrm{kcal} / \mathrm{mol}$. It is remarkable that the presence of four water molecules complexed to nicotine $\mathrm{H}^{+}$is enough to reverse the energy order between pyri- and pyrro- protonated conformations. Protonation on N12 provides pyrro conformations of roughly the same free energy than pyri ones. When 4 water molecules are present, free energies of 5.5 and $4.0 \mathrm{kcal} / \mathrm{mol}$ for the proton transfer are obtained by B3LYP and similar but slightly lower barrier by BLYP method, depending on the arrangement of the water molecules. It is also useful to note that the barrier of tautomerization for nicotine- $\mathrm{H}^{+}-$ $\left(\mathrm{H}_{2} \mathrm{O}\right)_{4}$ increases by $4-5 \mathrm{kcal} / \mathrm{mol}$, when the water continuum is added (IEFPCM model). This increase in the barrier amounts to the effects of the electrostatic water continuum, and the resulting barrier would be closer to that observed in the solution phase. These findings obtained by ab initio methods were also in agreement with the biased Car-Parrinello molecular dynamics (CPMD) simulations of the protontransfer process. ${ }^{44}$

\section{Conclusions}

In the present review, we discussed about the important role that water takes in affecting the structures and functions of biomolecules. We demonstrated that the solvent water may not only serve as electrostatic continuum, but it may also act as a direct participant in proton transfer, mediating and/or promoting the process. Experimental studies for these extremely interesting theoretical findings will be highly desirable.

Acknowledgments. This work was supported by Kyung Hee University (2009).

\section{References}

1. Alessandro, B., A.; Scorrano, G. Acc. Chem. Res. 2000, 33, 609.

2. Hibbert, F. Acc. Chem. Res. 1984, 17, 115. 
3. Peters, K. S. Acc. Chem. Res. 2009, 42, 89.

4. Lowry, T. H.; Richardson, K. S. Mechanism and Theory in Organic Chemistry; Harper \& Row: New York, 1987.

5. Anslyn, E. V.; Dougherty, D. A. Modern Physical Organic Chemistry; University Science Books: Sausalito, CA, 2006.

6. Frisch, M. J.; Trucks, G. W.; Schlegel, H. B.; Scuseria, G. E.; Robb, M. A.; Cheeseman, J. R.; Montgomery, J. A., Jr.; Vreven, T.; Kudin, K. N.; Burant, J. C.; Millam, J. M.; Iyengar, S. S.; Tomasi, J.; Barone, V.; Mennucci, B.; Cossi, M.; Scalmani, G.; Rega, N.; Petersson, G. A.; Nakatsuji, H.; Hada, M.; Ehara, M.; Toyota, K.; Fukuda, R.; Hasegawa, J.; Ishida, M.; Nakajima, T.; Honda, Y.; Kitao, O.; Nakai, H.; Klene, M.; Li, X.; Knox, J. E.; Hratchian, H. P.; Cross, J. B.; Bakken, V.; Adamo, C.; Jaramillo, J.; Gomperts, R.; Stratmann, R. E.; Yazyev, O.; Austin, A. J.; Cammi, R.; Pomelli, C.; Ochterski, J. W.; Ayala, P. Y.; Morokuma, K.; Voth, G. A.; Salvador, P.; Dannenberg, J. J.; Zakrzewski, V. G.; Dapprich, S.; Daniels, A. D.; Strain, M. C.; Farkas, O.; Malick, D. K.; Rabuck, A. D.; Raghavachari, K.; Foresman, J. B.; Ortiz, J. V.; Cui, Q.; Baboul, A. G.; Clifford, S.; Cioslowski, J.; Stefanov, B. B.; Liu, G.; Liashenko, A.; Piskorz, P.; Komaromi, I.; Martin, R. L.; Fox, D. J.; Keith, T.; Al-Laham, M. A.; Peng, C. Y.; Nanayakkara, A.; Challacombe, M.; Gill, P. M. W.; Johnson, B.; Chen, W.; Wong, M. W.; Gonzalez, C.; and Pople, J. A.; Gaussian, Inc., Wallingford CT, 2004.

7. Blom, M. N.; Compagnon, I.; Polfer, N. C.; Helden, G. V.; Meijer, G.; Suhai, S.; Paizs, B.; Oomens, J. J. Phys. Chem. A 2007, 111, 7309.

8. Xu, S.; Niles, J. M.; Bowen, K. H. J. Chem. Phys. 2003, 119, 10696.

9. Aikens, C. M.; Gordon, M. S. J. Am. Chem. Soc. 2006, 128, 12835.

10. Desfrancois, C.; Carles, S.; Schermann, J. P. Chem. Rev. 2000, 100, 3943.

11. Zwier, T. S. J. Phys. Chem. A 2001, 105, 8827.

12. Snoek, L. C.; Robertson, E. G.; Kroemer, R. T.; Simons, J. P. Chem. Phys. Lett. 2001, 321, 49.

13. Compagnon, I.; Hagemeister, F. C.; Antoine, R.; Rayane, D.; Broyer, M.; Dugourd, P.; Hudgins, R. R.; Jarrold, M. F. J. Am. Chem. Soc. 2001, 123, 8440.

14. (a) Ahn, D.-S.; Kang, A.-R.; Lee, S.; Kim, B.; Kim, S. K.; Neuhauser, D. J. Chem. Phys. 2005, 122, 084310. (b) Park, S.-W.; Im, S.; Lee, S.; Desfrancois, C. Int. J. Quantum Chem. 2007, 107, 1316.

15. (a) Ahn, D.-S.; Park, S.-W.; Jeon, I.-S.; Lee, M.-K.; Kim, N.-H.; Han, Y.-H.; Lee, S. J. Phys. Chem. B 2003, 107, 14109. (b) Park, S.-W.; Ahn, D.-S.; Lee, S. Chem. Phys. Lett. 2003, 371, 74.

16. (a) Jeon, I.-S.; Ahn, D.-S.; Park, S-.W.; Lee, S.; Kim, B. Int. J. Quantum Chem. 2005, 101, 55. (b) Jeon, I.-S.; Ahn, D.-S.; Park, S.-W.; Lee, S.; Kim, S. K. Chem. Phys. Lett. 2005, 403, 72.

17. Csaszar, A. G.; Perczel, A. Progr. Biophys. Mol. Biol. 1999, 71, 243.

18. Xu, S. J.; Zheng, W. J.; Radisic, D.; Bowen, K. H. J. Chem. Phys. 2005, 122, 091103 .
19. Snoek, L. C.; Kroemer, R. T.; Hockridge, M. R.; Simons, J. P. Phys. Chem. Chem. Phys. 2001, 3, 1819.

20. Spinor, J.; Sulkes, M. J. Chem. Phys. 1993, 98, 9389.

21. Im, S.; Jang, S.-W.; Lee, S.; Lee, Y.; Kim, B. J. Phys. Chem. A 2008, $112,9767$.

22. Fernandez-Ramos, A.; Smedarchina, Z.; Siebrand, W.; Zgierski, M. Z. J. Chem. Phys. 2000, 113, 9714.

23. Lemoff, A. S.; Bush, M. F.; Williams, E. R. J. Phys. Chem. A 2005, 109, 1903.

24. Hu, C. H.; Shen, M.; Schafer III, H. F. J. Am. Chem. Soc. 1993, 115,2923

25. Bandyopadhyay, P.; Gordon, M. S.; Mennucci, B.; Tomasi, J. J. Chem. Phys. 2002, 116, 5023.

26. Julian, R. R.; Jarrold, M. F. J. Phys. Chem. A 2004, 108, 10861.

27. Jensen, J. H.; Gordon, M. S. J. Am. Chem. Soc. 1995, 117, 8159.

28. Kim, J.-Y.; Schermann, J. P.; Lee, S. Bull. Korean Chem. Soc. 2010, 31, 59 .

29. Tortonda, F. R.; Pascual-Ahuir, J. L.; Silla, E.; Tunon, I. Chem. Phys. Lett. 1996, 260, 21.

30. Chapo, C. J.; Paul, J. B.; Provencal, R. A.; Roth, K.; Saykally, R. J. J. Am. Chem. Soc. 1998, 120, 12956.

31. Gdanitz, R. J.; Cardoen, W.; Windus, T. L.; Simons, J. J. Phys. Chem. A 2004, 108, 515 .

32. Julian, R. R.; Hodyss, R.; Beauchamp, J. L. J. Am. Chem. Soc. 2001, 123, 3577.

33. Jockusch, R. A.; Price, W. D.; Williams, E. R. J. Phys. Chem. A 1999, 103, 9266.

34. Bush, M. F.; O'Brien, J. T.; Prell, J. S.; Saykally, R. J.; Williams, E. R. J. Am. Chem. Soc. 2007, 129, 1612.

35. Rak, J.; Skurski, P.; Simons, J.; Gutowski, M. J. Am. Chem. Soc. 2001, 123, 11695.

36. Ling, S.; Yu, W.; Huang, Z.; Lin, Z.; Haranczyk, M.; Gutowski, M. J. Phys. Chem. A 2006, 110, 12282.

37. Laxer, A.; Major, D. T.; Gottlieb, H. E.; Fischer, B. J. Org. Chem. 2001, 66, 5463

38. Chenon, M. T.; Pugmire, R. J.; Grant, D. M.; Panzica, R. P.; Townsend, L. B. J. Am. Chem. Soc. 1975, 97, 4636.

39. Kim, H.-S.; Ahn, D.-S.; Chung, S.-Y.; Kim, S. K.; Lee, S. J. Phys. Chem. A 2007, 111, 8007.

40. Hanus, M.; Klabelac, M.; Rejnek, J.; Ryjacek, F.; Hobza, P. J. Phy. Chem. B 2004, 108, 2087.

41. Graton, J.; Berthelot, M.; Gal, J. F.; Girard, S.; Laurence, C.; Lebreton, J.; Le Questel, J. Y.; Maria, P. C.; Naus, P. J. Am. Chem. Soc. 2002, 124, 10552.

42. Seydou, M.; Gregoire, G.; Liquier, J.; Ortega, J. M.; Schermann, J. P.; Desfrancois, C. J. Am. Chem. Soc. 2008, 130, 4187.

43. Amiri, S.; Sansom, M.; Biggin, P. Protein Eng. Des. Sel. 2007, 20, 353.

44. Gaigeot, M.-P.; Cimas, A.; Seydou, M.; Kim, J.-Y.; Lee, S.; Schermann, J.-P. J. Am. Chem. Soc. 2010, 132, 18067. 